\title{
Effects of the Dietary Moisture Levels and Feeding Rate on the Growth and Gastric Evacuation of Young Olive Flounder Paralichthys olivaceus
}

\author{
Kyoung-Duck Kim ${ }^{1 *}$, Kang-Woong Kim ${ }^{1}$, Yong Jin Kang ${ }^{1}$, \\ Maeng Hyun Son ${ }^{1}$ and Sang-Min Lee ${ }^{2}$ \\ ${ }^{1}$ Aquafeed Research Center, National Fisheries Research and Development Institute, \\ Pohang 791-923, Korea \\ ${ }^{2}$ Faculty of Marine Bioscience \& Technology, Gangneung-Wonju National University, \\ Gangneung 210-702, Korea
}

\begin{abstract}
This study determined the effects of the dietary moisture level and feeding rate on the growth and gastric evacuation of young olive flounder. Four experimental diets with different moisture levels $(9 \%, 21 \%, 30 \%$, and $40 \%)$ were prepared through the addition of water to the commercial extruded pellet. Three replicate groups of fish (initial weight: 106 \pm 1.4 g) were fed diets containing $9 \%, 21 \%, 30 \%$, and $40 \%$ moisture to satiation or a moisture level of $9 \%$ and $30 \%$ at a restricted feeding rate ( $95 \%$ of satiation) for 15 weeks. The mean water temperature was $22 \pm 1.6^{\circ} \mathrm{C}$ during the feeding trial. Gastric evacuation rates were determined post-feeding. The dietary moisture levels did not significantly affect weight gain, but the weight of the fish receiving $9 \%$ and $30 \%$ moisture diets to $95 \%$ satiation were significantly lower than those of the fish fed $9-40 \%$ moisture diets to $100 \%$ satiation $(P<0.05)$. The feed efficiency, protein efficiency ratio, viscerosomatic index, and survival were not significantly affected by the dietary moisture levels and feeding rates. The daily feed intake of the fish fed to $100 \%$ satiation did not significantly differ among the treatment groups. The stomach contents that peaked within $3 \mathrm{~h}$ of feeding gradually decreased, and the stomachs of fish were completely evacuated within $18 \mathrm{~h}$. The contents of the intestine peaked at 3-12 h post-feeding, and then declined with the intestine being mostly evacuated at $30 \mathrm{~h}$. The moisture of the stomach contents reached approximately $70 \%$ within $3 \mathrm{~h}$ post-feeding and gradually increased to approximately $75 \%$ within $12 \mathrm{~h}$. No considerable differences were observed in the gastric evacuation and moisture levels of the stomach contents in the fish fed the different diets. The results of this study suggest that the gastric evacuation of olive flounder was not affected by the dietary moisture level and that the addition of water into the diet displayed no beneficial effects on the growth of young olive flounder.
\end{abstract}

Key words: Paralichthys olivaceus, Dietary moisture level, Feeding rate, Growth, Gastric evacuation, Olive flounder

\section{Introduction}

Olive flounder Paralichthys olivaceus is the most commercially important marine fish species for aquaculture in Korea. Numerous studies to determine the nutrient requirements or availability in the diets of olive flounder have been performed for the formulation of well nutritionally-balanced and cost-

(c) This is an Open Access article distributed under the terms of the Creative Commons Attribution Non-Commercial License (http://creativecommons.org/licenses/by-nc/3.0/) which permits unrestricted non-commercial use, distribution, and reproduction in any medium, provided the original work is properly cited. effective diets (Lee et al., 2000a, 2003; Kim and Lee, 2004). Dry pelleted diets have many advantages over wet diets including an ease of quality management and simple transport and storage. In addition, dry diets are better suited for use with automatic feeders and are generally more stable in water, causing less pollution. For these reasons, dry feeds are in widespread use for the cultivation of several fish species (Ghittino, 1972). However, the advantages of dry feed would be lost if a reduction in growth or

\footnotetext{
*Corresponding author: kdkim@nfrdi.go.kr

Copyright@The Korean Society of Fisheries and Aquatic Science
} 
feed utilization of the fish was observed.

The intake of water is essential for all aquatic and terrestrial animals (Adolph, 1933). This requirement can be met either by the direct intake of water or by chemical reactions in the body (metabolic water). Dietary water, which is usually noted as 'other dietary components' may require more attention as it can influence the digestive process and uptake of dietary nutrients. Water is the least expensive ingredient in fish feeds and its appropriate use may provide a cost-effective method of improving fish growth and uptake of other dietary ingredients. Previous studies have shown an improvement in growth and nutrient retention attributable to a faster nutrient release from the stomach and increased digestibility (Grove et al., 2001).

Gastric evacuation is affected by various factors, including water temperature, fish size, diet composition, and meal size (Bromley, 1987; Naik et al., 2000; Sweka et al., 2004). Information on the gastric evacuation rates of fish is useful to assess appetite return and allow an estimate of the proper feeding regimen. The feeding rate is one of the most important factors in the growth of fish (Brett, 1979). The optimum feeding rates not only enhance the growth, survival, and feed conversion ratio, but also assist the minimization of food wastage, size variation, and ultimate production costs.

In Korea, the majority of fish farmers supplement dry pelleted diets with water during olive flounder production. However, limited information on the effects of the additional water in the dry pellets is available. In this study, we investigated the effects of the dietary moisture and feeding rate on the growth and gastric evacuation of young olive flounder.

\section{Materials and Methods}

\section{Fish and rearing conditions}

Olive flounders were obtained from a local farm (Pohang, Korea). The fish were acclimated to rearing conditions for 4 weeks prior to initiating the feeding trial. After acclimatization, the fish (average weight, $106 \pm 1.4 \mathrm{~g}$ ) were randomly allocated to $181,500 \mathrm{~L}$ cylindrical plastic tanks with 20 fish in each tank. Filtrated seawater was supplied at a flow rate of 20 $\mathrm{L} / \mathrm{min}$ in each tank, and the water temperature was maintained at $22 \pm 1.6^{\circ} \mathrm{C}$ (mean $\pm \mathrm{SD}$ ). The photoperiod was left under natural conditions during the feeding trial. All fish in each tank were collectively weighed at the beginning of the feeding trial and every 5 weeks thereafter.

\section{Diets and feeding}

Four levels of dietary moisture were prepared: $9 \%$, $21 \%, 30 \%$, and $40 \%$. For the $9 \%$ moisture trial, commercial feed was used, while the $21 \%, 30 \%$, and $40 \%$ moisture levels were obtained through mixing the appropriate volume of deionized water $(15,30$, and $50 \mathrm{~g} / 100 \mathrm{~g}$ feed) to the commercial feed (Jeilfeed, Daejeon, Korea) (crude protein: 49.4\%, crude lipid: 12.9\%, ash: $9.2 \%)$. The moisture-containing pellets were stored at $-20^{\circ} \mathrm{C}$ until use.

Three replicate groups of fish were fed the experimental diets containing 9\%, 21\%, 30\%, and $40 \%$ moisture to satiation or $9 \%$ and $30 \%$ moisture at restricted feeding rates (95\% satiation) twice a day (09:00 and 16:00) for 15 weeks. Satiation feeding was determined by the point of cessation of the voluntary feeding activity of the fish. Uneaten food was removed and weighed after the fish had stopped eating and deducted from the feed consumption. The feed allowance of fish in the restricted feeding group was determined based on the average consumption of fish fed diets with the same moisture levels in the satiation feeding groups.

\section{Gastric evacuation}

Following the feeding trial, the gastric evacuation rates were measured using 14 fish from each tank. The fish were fed the experimental diets to visual satiety, while the other conditions were maintained in the feeding trial. The fish were anesthetized with 100 mg/L MS222 (Sigma, St. Louis, MO, USA) and killed for dissection of the gut. The feed contents, expressed as wet weight ( $\mathrm{g}$ ) of feed $\times 100 /$ fish (g), in the stomach and intestine (Brett and Higgs, 1970) were collected at 0 (immediately after feeding), 3, 6, $12,18,24$, and $30 \mathrm{~h}$ after feeding. The contents of the stomach and intestine were removed by gentle pressure.

\section{Sample collection and analytical methods}

At the end of the feeding trial, three fish from each tank were collected and stored at $-75^{\circ} \mathrm{C}$ for chemical analysis. The samples of diet, dorsal muscle, and the contents of the fish stomachs were analyzed for proximate composition. Crude protein was determined by the Kjeldahl method using the Auto Kjeldahl System (VAP50OT/TT125; Gerhardt, Königswinter, Germany). Crude lipid was determined by ether extraction using a Soxhlet extractor (Velp SER 148; Usmate, Milano, Italy). The moisture levels were determined by oven-drying at $135^{\circ} \mathrm{C}$ for $2 \mathrm{~h}$. Ash was determined using a muffle furnace at $550^{\circ} \mathrm{C}$ for $6 \mathrm{~h}$. 


\section{Statistical analyses}

The data were subjected to a one-way analysis of variance (ANOVA), and when significant $(P<0.05)$ differences were observed, a Duncan's multiple range test (Duncan, 1955) was used to rank the groups using the SPSS program version 11.5 for Windows (SPSS Inc., Chicago, IL, USA).

\section{Results}

\section{Growth performance and body composition}

The growth performances of fish receiving the $9 \%$, $21 \%$, $30 \%$, and $40 \%$ moisture diets at a different feeding rate for 15 weeks are shown in Table 1 . The dietary moisture levels did not significantly affect the weight gain or the specific growth rate. However, the weight gain and specific growth rate of the fish fed $9 \%$ and $30 \%$ moisture diets to $95 \%$ satiation were significantly lower than those of fish receiving 9-40\% moisture diets to $100 \%$ satiation $(P<0.05)$. The feed efficiency, protein efficiency ratio, viscerosomatic index, and survival rates were not significantly affected by the dietary moisture levels and feeding rate. The daily feed intake of fish fed to $100 \%$ of satiation did not significantly differ among the treatment groups.

The approximate composition of the dorsal muscle in the fish fed $9 \%, 21 \%, 30 \%$, and $40 \%$ moisture diets at different feeding rates for 15 weeks are shown in Table 2. The moisture, crude protein, and crude lipid content of the dorsal muscle did not significantly differ among the groups.

\section{Gastric evacuation}

The gastric contents of the fish receiving the various moisture diets are shown in Fig. 1. The stomach contents peaked within $3 \mathrm{~h}$ of feeding and gradually decreased thereafter with the stomachs of the fish being completely evacuated within $18 \mathrm{~h}$. The contents of the intestine peaked at 3-12 h post-feeding and began to decline at $30 \mathrm{~h}$ until the intestine was almost completely evacuated. The moisture of the stomach contents in the various diets are shown in Fig. 2. The moisture of the stomach contents reached approximately $70 \%$ within $3 \mathrm{~h}$ post-feeding and gradually increased to approximately $75 \%$ within $12 \mathrm{~h}$. No considerable differences were observed in the gastric evacuation and stomach moisture content in the fish receiving the different moisture diets.

Table 1. Growth performance of young olive flounder fed the extruded pellet with the different moisture levels and feeding rates for 15 weeks

\begin{tabular}{|c|c|c|c|c|c|c|}
\hline \multirow{2}{*}{$\begin{array}{l}\text { Dietary moisture (\%) } \\
\text { Feeding rate }\end{array}$} & 9 & 21 & 30 & 40 & 9 & 30 \\
\hline & \multicolumn{4}{|c|}{ Satiation } & \multicolumn{2}{|c|}{ 95\% Satiation } \\
\hline Initial mean weight (g/fish) & $107 \pm 1.0^{\text {ns }}$ & $105 \pm 0.2$ & $106 \pm 0.8$ & $107 \pm 0.5$ & $107 \pm 1.6$ & $107 \pm 0.4$ \\
\hline Weight gain (g/fish) & $203 \pm 2.2^{\mathrm{a}}$ & $197 \pm 7.9^{\mathrm{a}}$ & $199 \pm 10.0^{a}$ & $194 \pm 1.9^{\mathrm{a}}$ & $171 \pm 4.4^{\mathrm{b}}$ & $172 \pm 5.2^{\mathrm{b}}$ \\
\hline Specific growth rate (\%) ${ }^{*}$ & $1.54 \pm 0.01^{\mathrm{a}}$ & $1.52 \pm 0.04^{\mathrm{a}}$ & $1.52 \pm 0.05^{\mathrm{a}}$ & $1.50 \pm 0.00^{\mathrm{a}}$ & $1.38 \pm 1.26^{\mathrm{b}}$ & $1.39 \pm 0.02^{b}$ \\
\hline Feed efficiency $(\%)^{\dagger}$ & $114 \pm 0.8^{\mathrm{ns}}$ & $114 \pm 1.9$ & $113 \pm 1.6$ & $111 \pm 1.5$ & $112 \pm 2.0$ & $110 \pm 0.5$ \\
\hline Protein efficiency ratio ${ }^{\ddagger}$ & $2.15 \pm 0.02^{\text {ns }}$ & $2.14 \pm 0.04$ & $2.13 \pm 0.03$ & $2.08 \pm 0.03$ & $2.11 \pm 0.04$ & $2.07 \pm 0.01$ \\
\hline Daily feed intake $(\%)^{\S}$ & $1.22 \pm 0.01^{\mathrm{a}}$ & $1.21 \pm 0.03^{\mathrm{ab}}$ & $1.18 \pm 0.03^{\mathrm{abc}}$ & $1.22 \pm 0.02^{\mathrm{a}}$ & $1.14 \pm 0.01^{\mathrm{bc}}$ & $1.12 \pm 0.03^{\mathrm{c}}$ \\
\hline Viscerosamatic index" & $1.96 \pm 0.05^{\text {ns }}$ & $1.94 \pm 0.09$ & $2.02 \pm 0.06$ & $1.82 \pm 0.08$ & $1.83 \pm 0.05$ & $1.89 \pm 0.12$ \\
\hline Survival (\%) & $100 \pm 0.1^{\text {ns }}$ & $98 \pm 1.7$ & $95 \pm 2.9$ & $98 \pm 1.7$ & $100 \pm 0.1$ & $97 \pm 3.3$ \\
\hline
\end{tabular}

Values (mean \pm SE of three replications) not sharing a superscript are significantly different $(P<0.05)$.

Ns, not significant $(P>0.05)$.

${ }^{*}$ [(Ln final weight of fish - Ln initial weight of fish) $\left.\times 100\right]$ /days of feeding, ${ }^{\dagger}$ Fish wet weight gain $\times 100 /$ feed intake (dry matter). ${ }^{\ddagger}$ Fish wet weight gain/protein intake, ${ }^{8}$ Feed intake (dry matter) $\times 100 /[$ (initial fish weight + final fish weight + dead fish weight) $\times$ days fed/2], "Viscera weight $\times 100 /$ body weight.

Table 2. Proximate composition of the dorsal muscle in young olive flounder fed the extruded pellet with the different moisture levels and feeding rates for 15 weeks

\begin{tabular}{|c|c|c|c|c|c|c|}
\hline \multirow{2}{*}{$\begin{array}{l}\text { Dietary moisture (\%) } \\
\text { Feeding rate }\end{array}$} & 9 & 21 & 30 & 40 & 9 & 30 \\
\hline & \multicolumn{4}{|c|}{ Satiation } & \multicolumn{2}{|c|}{ 95\% Satiation } \\
\hline Moisture (\%) & $76.4 \pm 0.12^{\mathrm{ns}}$ & $76.4 \pm 0.13$ & $76.4 \pm 0.03$ & $76.4 \pm 0.04$ & $76.3 \pm 0.09$ & $76.0 \pm 0.18$ \\
\hline Crude protein (\%) & $21.9 \pm 0.16^{\mathrm{ns}}$ & $21.9 \pm 0.19$ & $21.6 \pm 0.10$ & $21.9 \pm 0.05$ & $21.9 \pm 0.15$ & $22.0 \pm 0.10$ \\
\hline Crude lipid (\%) & $0.2 \pm 0.02^{\mathrm{ns}}$ & $0.2 \pm 0.03$ & $0.3 \pm 0.01$ & $0.2 \pm 0.02$ & $0.2 \pm 0.02$ & $0.2 \pm 0.01$ \\
\hline
\end{tabular}

Values are mean $\pm \mathrm{SE}$ of three replications.

Ns, not significant $(P>0.05)$. 

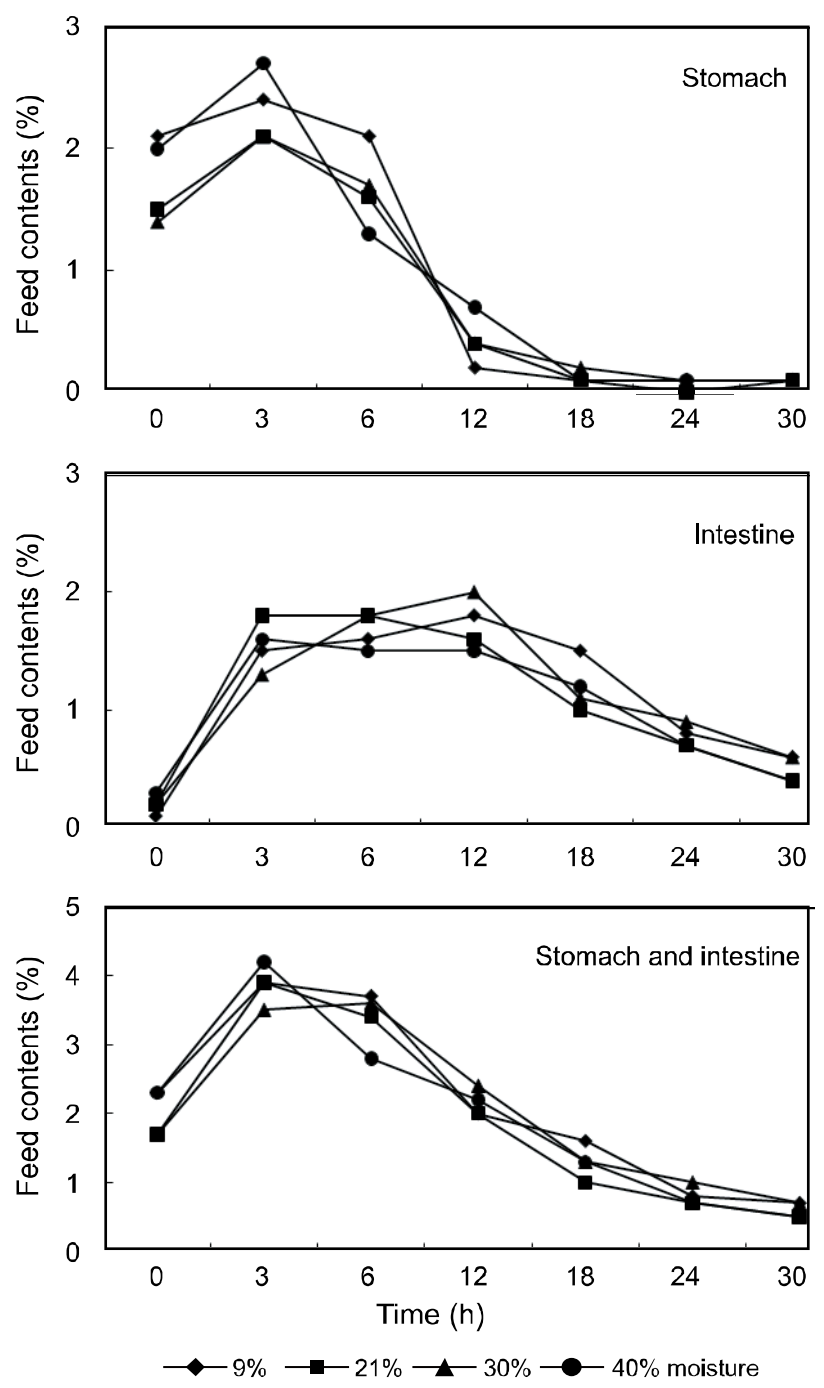

Fig. 1. Gastric feed contents of young olive flounder fed the extruded pellets with the different moisture levels.

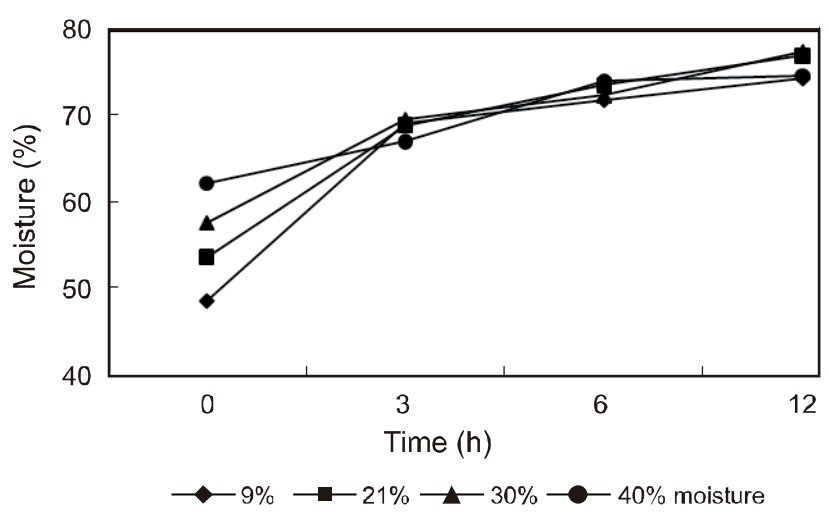

Fig. 2. Moisture of stomach feed contents in young olive flounder fed the extruded pellets with the different moisture levels.

\section{Discussion}

In this study, an increase in dietary moisture from $9 \%$ to $40 \%$ displayed no beneficial effects on the growth and feed utilization of olive flounder (106 g average initial weight). Similar nonsignificant differrences for the weight gain and feed efficiency were observed in the subadult flounder (332 g) fed diets containing $7-15 \%$ moisture under the rearing water temperature of $21^{\circ} \mathrm{C}$, as well as in $646 \mathrm{~g}$ flounder fed between $8 \%$ and $23 \%$ moisture diets at the suboptimal water temperature of $12^{\circ} \mathrm{C}$ (Kim et al., 2011). Lee et al. (2000b) reported that dietary moisture content displayed no significant effects on the weight gain or feed efficiency of Korean rockfish Sebastes schlegeli, but Chatzifotis et al. (2005) reported that dentex Dentex dentex grew more effectively when receiving diets containing 20\% moisture compared to $7 \%$ or $40 \%$ moisture levels. In Atlantic cod Gadus morhua, the specific growth rates increased with an increasing dietary water content of $0 \%$ to $50 \%$ (Otterå et al., 1994), while Grove et al. (2001) reported that the growth of turbot Scophthalmus maximus increased when fed a moist rather than a dry diet.

Marine fish may require dietary water for osmoregulation between the body and medium (Ruyet et al., 1982; Higgs et al., 1985), and the growth-promoting effect of moisturized diets could be attributable to a faster nutrient release from the stomach, leading to higher digestibility (Grove et al., 2001). Other reasons for the improved growth when receiving moist diets include an improved acceptance of soft versus hard feed particles (Stradmeyer et al., 1988). For dentex, fish fed $7 \%$ water diets displayed smaller stomachs than those fed a $40 \%$ water diet (Chatzifotis et al., 2005). The stomach volumes of the herring diet-fed rainbow trout Oncorhychus mykiss were significantly larger than those fed a dry diet (Ruohonen and Grove, 1996). The effect of dietary moisture content on the performance of fish is generally thought to vary depending on the fish species.

This study showed a similar stomach moisture content in fish fed diets of varying moisture levels within $3 \mathrm{~h}$ of feeding. Similarly, after feeding, the feed was hydrated, and within $2 \mathrm{~h}$, the stomach digesta reached similar water content levels to dentex that had received $7 \%, 20 \%$, and $40 \%$ water diets (Chatzifotis et al., 2005). Fish require moisturized ingested food prior to digestion (Hughes and Barrows, 1990) and dry pellets impose a demand for water during gastric processing. Fish hydrate their digesta 
through drinking during ingestion and stomach secretion (Kristiansen and Rankin, 2001). The ability of fish to moisturize their digesta varies on the fish species (Hughes and Barrows, 1990). A higher water content (70\%) in the stomach digesta of olive flounder $3 \mathrm{~h}$ post-feeding was observed in this study compared to the $60 \%$ reported for dentex (Chatzifotis et al., 2005). Certain species not being able to moisturize their digesta may decrease their efficiency of digestion, resulting in a reduced growth performance (Hughes and Barrows, 1990).

The gastric contents of fish are affected by properties of the diet including its composition of ingredients and its moisture content (Poston, 1974; Grove et al., 1978; Sveier et al., 1999). However, the results of this study indicate that the gastric evacuation rates of olive flounder were not affected by the dietary moisture content. Similarly, Garber (1983) reported no significant differences in the evacuation rates between yellow perch fed $4.7 \%$ and $27.1 \%$ moisture diets. For dentex, no differences in the gastric evacuation rates were observed among fish fed diets containing $7 \%, 20 \%$, and $40 \%$ moisture (Chatzifotis et al., 2005). In this study, at $30 \mathrm{~h}$ postfeeding, the intestine of the flounder was primarily evacuated. However, subadult flounder (848 g) fed diets containing $8 \%$ and $23 \%$ moisture under a rearing water of $12^{\circ} \mathrm{C}$ required $56 \mathrm{~h}$ to evacuate their intestines in previous studies (Kim et al., 2011). The variations in gastric evacuation time may be due to differences in the fish size, the dietary composition, or the water temperature employed during these studies.

Olive flounder in the restricted feeding groups showed considerably lower weight gain than that of fish of the satiated feeding group. Similar results have been reported in previous flounder studies (e.g., Cho et al., 2006). Under conditions of restricted feeding, fish tend to optimize their digestion to utilize the nutrients in the feed more efficiently, thereby increasing the feed conversion. Studies on several fish species have shown that an improved feed efficiency is achieved at levels slightly below satiation (Hung et al., 1989; Mihelakakis et al., 2002; Eroldogan et al., 2004). In this study, however, the feeding efficiency of flounder was not significantly affected by the feeding rates, consistent with previous studies (Seo et al., 2005a, 2005b; Cho et al., 2006), most likely because the weight gain of the fish increased proportionally with the increase in feed consumption (Cho et al., 2006).

The proximate composition of the dorsal muscle was not affected by the dietary moisture levels and feeding rates in this study, consistent with previous reports (e.g., Seo et al., 2005b). In this regard, Lee et al. (2000b) showed that the chemical composition of the dorsal muscle in rockfish fed dry and moist pellets did not significantly differ.

Taken together, this study demonstrates that the gastric evacuation of olive flounder is not affected by dietary moisture levels and that the addition of water into the diet displays no beneficial effects on the growth of olive flounder.

\section{Acknowledgments}

This work was funded by grant from the National Fisheries Research and Development Institute (RP2011-AQ-007).

\section{References}

Adolph EF. 1933. The metabolism and distribution of water in body and tissues. Physiol Rev 13, 336-371.

Brett JR. 1979. Environmental factors and growth. In: Fish Physiology. Bioenergetics and Growth. Hoar WS, Randall DJ, Brett JR, eds. Academic Press, New York, NY, US, pp. 599-675.

Brett JR and Higgs DA. 1970. Effect of temperature on the rate of gastric digestion in fingerling sockeye salmon, Oncorhynchus nerka. J Fish Res Board Can 27, 17671779.

Bromley PJ. 1987. The effects of food type, meal size and body weight on digestion and gastric evacuation in turbot, Scophthalmus maximus L. J Fish Biol 30, 501512.

Chatzifotis S, Papadakis IE and Divanach P. 2005. Effect of dietary water on growth of dentex Dentex dentex. Fish Sci 71, 1243-1248.

Cho SH, Lee SM, Park BH and Lee SM. 2006. Effect of feeding ratio on growth and body composition of juvenile olive flounder Paralichthys olivaceus fed extruded pellets during the summer season. Aquaculture 251, 78-84.

Duncan DB. 1955. Multiple-range and multiple F tests. Biometrics 11, 1-42.

Eroldogan OT, Kumlu M and Aktas M. 2004. Optimum feeding rates for European sea bass Dicentrachus labrax L. reared in seawater and freshwater. Aquaculture 231, 501-515.

Garber KJ. 1983. Effect of fish size, meal size and dietary moisture on gastric evacuation of pelleted diets by yellow perch, Perca flavescens. Aquaculture 34, 4149.

Ghittino P. 1972. The diet and general fish husbandry. In: Fish Nutrition. Halver JE, ed. Academic Press, New 
York, NY, US, pp. 539-649.

Grove D, Genna R, Paralika V, Boraston J, Hornyold MG and Siemens R. 2001. Effects of dietary water content on meal size, daily food intake, digestion and growth in turbot, Scophthalmus maximus (L.). Aquac Res 32, 433-442.

Grove DJ, Loizides LG and Nott J. 1978. Satiation amount frequency of feeding and gastric emptying rate in Salmo gairdneri. J Fish Biol 12, 507-516.

Higgs DA, Markert JR, Plotnikoff MD, McBride JR and Dosanjh BS. 1985. Development of nutritional and environmental strategies for maximizing the growth and survival of juvenile pink salmon (Oncorhynchus gorbuscha). Aquaculture 47, 113-130.

Hughes SG and Barrows R. 1990. Measurements of the abilities of cultured fishes to moisturize their digesta. Comp Biochem Physiol A Physiol 96, 109-111.

Hung SSO, Lutes PB, Conte FS and Storebakken T. 1989. Growth and feed efficiency of white sturgeon (Acipenser transmontanus) sub-yearlings at different feeding rates. Aquaculture 80, 147-153.

Kim KD and Lee SM. 2004. Requirement of dietary n-3 highly unsaturated fatty acids for juvenile flounder (Paralichthys olivaceus). Aquaculture 229, 315-323.

Kim KD, Kim DG, Kim KW, Nam MM, Lee JY, Kang YJ, Son $\mathrm{MH}$ and Lee SM. 2011. Effects of dietary moisture content on the growth and gastrointestinal evacuation of sub-adult olive flounder (Paralichthys olivaceus) in the summer and winter seasons. Kor $\mathrm{J}$ Fish Aquat Sci 44, 149-154.

Kristiansen HR and Rankin JF. 2001. Discrimination between endogenous and exogenous water sources in juvenile rainbow trout fed extruded dry feed. Aquat Living Resour 14, 359-366.

Lee SM, Cho SH and Kim KD. 2000a. Effects of dietary protein and energy levels on growth and body composition of juvenile flounder Paralichthys olivaceus. J World Aquac Soc 31, 306-315.

Lee SM, Hwang UG and Cho SH. 2000b. Effects of feeding frequency and dietary moisture content on growth, body composition and gastric evacuation of juvenile Korean rockfish (Sebastes schlegeli). Aquaculture 187, 399-409.

Lee SM, Kim KD and Lall SP. 2003. Utilization of glucose, maltose, dextrin and cellulose by juvenile flounder (Paralichthys olivaceus). Aquaculture 221, 427-438.

Mihelakakis A, Tsolkas C and Yoshimatsu T. 2002.
Optimization of feeding rate for hatchery-produced juvenile gilthead sea bream Sparus aurata. J World Aquac Soc 33, 169-175.

Naik MK, Reddy HRV and Annappaswamy TS. 2000. Influence of diet composition, starvation and feeding frequency on gastric evacuation rates on Catla, Catla catla (Hamilton) fingerlings. Indian J Anim Sci 70, 1090-1093.

Otterå H, Hemre GI and Lie Ø. 1994. Influence of dietary water content on feed intake, growth and survival of juvenile Atlantic cod, Gadus morhua L., during the weaning process. Aquac Res 25, 915-926.

Poston HA. 1974. Effect of feeding brown trout (Salmo trutta) a diet pelleted in dry and moist forms. J Fish Res Board Can 31, 1824-1826.

Ruohonen K and Grove DJ. 1996. Gastrointestinal responses of rainbow trout to dry pellet and low-fat herring diets. J Fish Biol 49, 501-513.

Ruyet JPL, Noël T, Nédélec G and Souchu PL. 1982. Effects of moist pelleted foods on the growth of hatchery turbot (Scophthalmus maximus) juveniles. J World Maric Soc 13, 237-245.

Seo JY, Jang HS, Kim KD, Kim GU and Lee SM. 2005a. Effects of dietary composition, feeding satiation rate and feeding frequency of extruded pellets on growth and body composition of flounder Paralichthys olivaceus. J Aquac 18, 98-106.

Seo JY, Lee JH, Kim GU and Lee SM. 2005b. Effects of extruded and moist pellets at different feeding rate on growth and body composition of juvenile flounder Paralichthys olivaceus. J Aquac 18, 26-30.

Stradmeyer L, Metcalfe NB and Thorpe JE. 1988. Effect of food pellet shape and texture on the feeding response of juvenile Atlantic salmon. Aquaculture 73, 217-228.

Sveier H, Wathne E and Lied E. 1999. Growth, feed and nutrient utilisation and gastrointestinal evacuation time in Atlantic salmon (Salmo salar L.): the effect of dietary fish meal particle size and protein concentration. Aquaculture 180, 265-282.

Sweka JA, Keith Cox MK and Hartman KJ. 2004. Gastric evacuation rates of brook trout. Trans Am Fish Soc 133, 204-210.

(Received 31 March 2011; Revised 3 May 2011; Accepted 16 May 2011) 